\title{
Stories the mangroves hold Reflections on Indo-Caribbean feminist community archiving
}

Ro(u)ted by Our Stories Collective

Ro(u)ted by Our Stories Collective is a US-based collective of eight women and gender-expansive people

\section{ABSTRACT}

This article invites the reader into conversation about silenced stories, intergenerational connection and what it means to reimagine Indo-Caribbean feminist histories. The authors of this article are coauthors of a digital archive, Ro(u)ted by Our Stories, which centres the stories of Indo-Caribbean women and those of marginalised genders in the US across generations. In this piece, we draw from historical material, our lived experiences as descendants of indenture, and a recorded conversation we had between members of our collective about our experiences working to create a community-owned digital archive. We share our visions for creating the archive and questions we have grappled with throughout the process, including our own limitations and reflections on archives as always unfinished and incomplete. Furthermore, we discuss the ways in which we see storytelling as a healing practice, our efforts to remain grounded in the needs and desires of community members and our hopes for the future of the archive. By including multiple voices in this piece, we hope to lift up the collaboration, interdependence and 'weaving together' of stories that informs the lens we bring to this work.

\section{KEYWORDS}

Indo-Caribbean archive, Indo-Caribbean feminism, oral history Indo-Caribbean, intergenerational silence, domestic violence IndoCaribbean 


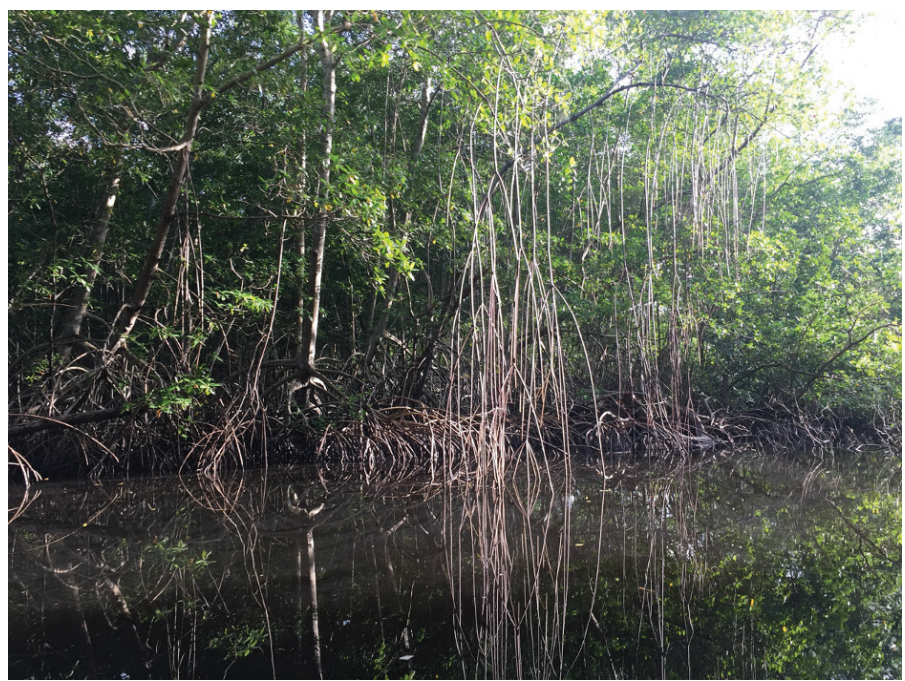

Caroni Swamp, 2017

\section{EPIGRAPH}

Sasha: We discussed that mangrove trees are present in the Indian subcontinent, in the Caribbean, and North America. The mangroves themselves are geographically distant in these different areas of the world, but in spite of that, similar to our communities, they have interconnected roots. Their seeds are pods that drop off and travel to places where they can thrive. It's amazing because that's also parallel to journeys that were taken from the Indian subcontinent to the Caribbean.

Lissa: The roots of the mangrove tree are not buried underground. They are a very important, integral part of its structure and also of its visual identity. Just like our ancestors, the mangroves crossed the Kala Pani too, and they took their own route and ended up with us. I think it's also really interesting the way we play on roots/routes, because stories, they don't just exist. They travel, they grow, they interconnect. There's no singular story.

Kimmi: The Caroni Swamp in Trinidad is one of my favorite places and that's what I was thinking about when I was thinking about mangroves 
and I brought the idea of the mangrove tree as the logo to folks. If y'all ever have a chance to go, it's so beautiful, and the Scarlet Ibis is the national bird of Trinidad. They fly in and roost in the swamp, but it's also a really dangerous place.

Tarika: This idea of the mangrove turning up in unexpected places, wherever life takes you, which is so much the story of our diasporatravelling to these different places and ending up maybe where you don't expect, but finding a sense of home there.

\section{INTRODUCTION}

We begin this piece with an excerpt from a conversation between members of our collective, Ro(u)ted by Our Stories (RbOS), about a recurring motif in our work: the mangrove. We introduce ourselves through this motif to guide the reader through how we approach our affiliations with each other and the intersecting journeys of our indentured ancestors. We are a collective of IndoCaribbean women and gender expansive people in the United States who believe in the transformative power of storytelling across generations. In this piece, we invite you into conversation about silenced stories, intergenerational connection and what it means to document Indo-Caribbean feminist histories.

We came together in 2019 to co-create a community-owned digital archive called Ro(u)ted by Our Stories: Silenced Indo-Caribbean Voices Speak. $\mathrm{RbOS}$ is an intergenerational oral history archive dedicated to capturing, preserving and sharing stories from women and those of marginalised genders at various intersections of identity. From January to March of 2019, one of our members partnered with Jahajee Sisters, an Indo-Caribbean gender justice organisation in New York City, to conduct a three-part oral history workshop with 12 Indo-Caribbean women and gender expansive people across generations. The participants of the workshop shared their experiences with oral history, discussed the importance of oral history in our communities, engaged in deep listening and trust-building exercises together, and began to 
explore the stories they each brought with them to the space. After co-creating an interview guide, participants recorded oral history interviews of one another, taking turns as speaker and as listener.

Our collective was formed after the interviews were done through shared interest in building on this collection of stories and creating a community-owned digital archive. Over the course of 11 months, a group of nine of us met bi-weekly to share our dreams and goals with each other, define our work together and build community. After many hours of transcribing the interviews, creating the website, compiling resources and creating a process for visitors to the site to submit their interviews to us, we held a launch event in Queens where community members were invited to listen to the interviews, share their own stories and give feedback on the website. It was a day full of laughter, food and deep discussion about the sacredness of our stories that shaped the current phase of our work one of reflection and revisioning of the work we are doing together, and connection with others who are negotiating similar possibilities and challenges with community archiving.

We enter into this work from multiple positions; we are scientists, academics, artists, activists, librarians, youth workers and documentary filmmakers. We also enter this work from our lived experiences as Indo-Caribbean women and gender expansive people in the US who rarely see the histories of our communities represented in our textbooks or media, among other places. We are descendants of indenture, an exploitative system of contractual labour developed under colonialism after the emancipation of enslaved Black people in the British Caribbean in 1834. Our histories are intertwined with that of the African diaspora and transatlantic slavery, as indentureship was proposed as a labour system to replace slavery in the colonies. Although indenture had many historical iterations and a wide geographic span, the members of our collective are the descendants of indentured laborers who were brought from the South Asian subcontinent to the Caribbean beginning in 1838 . 
The migration of our ancestors from India to the Caribbean and other sites of indenture was a traumatic displacement, compounded by the dehumanising labour, violence and patriarchal oppression embedded in indentureship, all of which become part of our intergenerational inheritance. The voices of indentured Indian women were doubly silenced on the basis of race and gender, as Gaiutra Bahadur skilfully explores as she works to piece together the story of her great-grandmother, Sujaria, who was brought over from India to Guyana as an indentured labourer (Bahadur 2013). As historian and Caribbean feminist scholar Verene Shepherd notes, 'The task of uncovering the historical experiences of Indian woman is not an easy one, for colonialist historiography has tended to mute the voices of exploited people', and even more so, 'the subaltern, as female' (2002: 107). If the stories of Indo-Caribbean women are marginalised and underrepresented, then the members of our community who are LGBTQ+, queer and identify beyond the gender binary are rendered even more invisible in the archives of the diaspora. As Aliyah Khan cautions, 'The possibility with which we must contend is that [...] while questing for queers in the historical record may uncover a few instances of interest, we may not find the ancestor we are looking for' (2016: 249). Our community archive attempts to move toward rectifying these gaps in the archive. The oral histories that have been shared with us challenge the patriarchal, heteronormative, single-lens view of Indo-Caribbean history. As members of the 'double-diaspora', who have since not only migrated from India to the Caribbean but the Caribbean to the US, we are conscious also of the "multiple exiles that are a part of the Indian [or Indo-Caribbean] experience in the Caribbean and North America' (Mehta 2006: 19).

The knowledge sources we draw from in this piece and in our work more broadly reflect the multiplicity of our identities and experiences. We draw imperfectly from academic sources that have moved us in our work together, but do not consider the citations we have included here to be complete. Instead, we foreground our 
embodied and experiential knowledge and return to the concept of the archive in a way that is grounded in our voices.

At the same time, we recognise the importance of those who have come before us who have written about the intersections of storytelling and gender justice in Indo-Caribbean communities, and we do not consider academic knowledge and embodied/experiential knowledge to be mutually exclusive. We intentionally place our voices and embodied theories alongside published academic works. We draw from our lived experiences and the experiences that people close to us have shared with us; the knowledge our grandparents have passed down; and knowledge we have learned through relationships with one another in community. And we are inspired by and acknowledge the thinkers and theorisers who have come before us on our journeys to understand the legacies of the past. We acknowledge these thinkers in our bibliography of works that we have cited throughout this piece, and works we have consulted. Our work is implicitly and explicitly indebted to the Indo-Caribbean, Afro-Caribbean, diasporic and other intellectuals who have come before us, as well as our indentured and post-abolition forebears who may never be named in a book or scholarly article.

\section{METHOD}

The purpose of this piece is to engage in collective reflection about themes of language, orality, silence, community-building and futurity in our archival work. The importance of personal narrative to advancing theory has long been argued by critical race and feminist scholars, and guides our method of centring our lived experiences and knowledge that we have gained by being in community with one another. Several conversations are happening simultaneously in this piece. First, each section opens with excerpts from a recorded conversation we had between members of our collective about our experiences building this collective and the archive. The next conversation happens within the text itself, as it includes our multiple 
voices as co-writers of the piece. Following each excerpt are our reflections on the themes that came up in the recorded conversation. We analysed the transcript of this conversation together, with each member of the collective involved at various stages of the process, from identifying aspects of the transcript that stood out to us to generating and expanding on the themes.

The other conversation is the one we are having with you, our reader. We imagined the multiple audiences that might come into contact with our piece, including other Indo-Caribbean feminists interested in community oral history and digital archiving, and we hope that you find resonance with the reflections and questions that have emerged for us. We share our visions for creating the archive and questions we have grappled with throughout the process, including our own limitations and reflections on archives as always unfinished and incomplete. We discuss the ways in which we see storytelling as a healing practice, our efforts to remain grounded in the needs and desires of community members, and our hopes for the future of the archive. By including multiple voices in this piece, we hope to lift up the collaboration, interdependence and 'weaving together' of stories that informs the lens we bring to this work.

\section{LANGUAGE AND NAMING}

Tarika: One of the parts of the process that stood out for me that I still remember so vividly are these really intense conversations where we were struggling with language, but struggling in a good way - thinking about the terminology we were using. So a lesson that really stuck with me from that was the idea of language as always being incomplete and imperfect and just being really transparent about that.

Kimmi: Acknowledging the people who we learned from and citing them also feels really important because we're doing this as part of a legacy, and that felt like something that we were intentional about. 
Lissa: [Touching on] the part of our name after the colon, we replaced the very specific phrase of 'women and gender non-conforming people' with 'silenced voices' because we don't know whose voices will be silenced in the future. We don't know what will be considered silenced in the future.

How communities choose to name themselves reveals a great deal about how they are positioning themselves in relation to other people. By naming ourselves as a collective of IndoCaribbean women and gender expansive people, we locate ourselves within a long legacy of resistance by our communities, while acknowledging that the stories that come from our communities can both subvert and be complicit in reinforcing historical oppression. How we talk about ourselves reveals our desires for connection with those in the past, present and future who are committed to issues of justice. At the same time, our language is incomplete and imperfect, just as the stories of our archive are. The constant evolution of language, and language as an inherently imperfect structure, was - and is - a key component of the development of our archive. From naming the archive, contemplating terminology that would describe our identities, to deciding how we transcribed the spoken words of our oral history narrators, we sat in deep reflection about our usage of language from multiple angles.

When we imagined this archive into existence, a large part of our conversation centred on how we would name the communities we hold ourselves accountable to. This process involved many iterations and collective reflection on what we understand to be 'silenced' stories, identifying who sits at the margins of our communities, and whose experiences we can and cannot speak for. When we named our collective Ro(u)ted by Our Stories, we incorporated Paul Gilroy's (1993) concept of roots/routes, which he developed in relation to the transatlantic slave trade. We understand the history of slavery to be intertwined with the history of indentureship, yet the experiences of our South Asian-descended 
ancestors are not the same as the experiences of our Africandescended ancestors. Where we found resonance in the metaphor of roots/routes was in its departure from understandings of identity that focus on authenticity and narrow views of origin and instead on identity as fluid, mobile and ever-evolving.

The name of our archive, Ro(u)ted by Our Stories: Silenced IndoCaribbean Voices Speak, raises the question - what do we mean by silenced stories? When we first began collecting the oral histories that now live in our archive, we sought to document the gendered legacies of indentureship and how the intersections of colonialism and patriarchy shape people's lives and experiences, and were guided by a shared understanding that the stories women and gender expansive people tell would illuminate broader societal patterns.

Through the interviews, we came to realise that silencing was happening at multiple intersections of oppression, including sexuality, race, religion, disability, education, etc. We follow in the tradition of scholars of intersectionality who argue that questions of gender justice cannot be separated from questions of migrant justice; migrant justice cannot be separated from questions of LGBTQ liberation and so on. We adopted the language of 'silenced stories' to hold ourselves accountable to ongoing reflection about whose stories are missing, and whose stories have yet to be recognised as missing.

\section{ORAL TRADITIONS, STORYTELLING AND THE ARCHIVE}

Kimmi: The orality of our culture feels really important. Most of my favorite childhood memories are of my grandfather telling me stories. While I feel like storytelling has always been a big part of how I've experienced my grandparents, especially, there's so many stories that would've been really helpful to know that I've only learned as I've gotten older. 
Lissa: I'll always say to my father, 'Tell me that one story about you and the green snake. Tell me the one about Grandma and the umbrella.' The only reason a lot of our parents know the stories about where they come from is because of oral histories because they didn't have any actual documents to look back at. I think it feels very natural to document Caribbean history through oral history because it's a very comfortable way for our community to get their stories across.

To speak and name one's experience is a transformative practice because it is both personal and political. There are few first-person accounts of indenture that are widely available or easily accessed, and when indentured women appear in the archives, it is often because of the high rates of violence they faced. Most frequently, they appear in reports from white plantation officers detailing incidences of sexual and domestic violence (Bahadur 2013). Indentured labourers who were gender expansive and gender non-conforming are largely absent from archives and historical narratives, despite a long history of the existence of more than two genders in the South Asian subcontinent and its diasporas (Agrawal 1997). Yet, the memory of indenture lives on through the stories we inherit from elders, the songs our people sing, in the ways we share joy with one another, but also in the ways we enact harm on each other.

The stories we have inherited communicate knowledge about our ancestors' struggles and ways of surviving. Constructions of Indo-Caribbean identity, both individually and collectively, are informed by and rely on oral traditions. Orality is the conduit through which ancestral history, traditions, recipes and religious and healing practices are shared. When people who were to become indentured laborers boarded the ships to cross the Kala Pani, or black waters, from South Asia to the Caribbean, they had few material possessions and were limited to bringing only what they could carry, yet they had an abundance of memories to share and knowledge to pass on. Like other intergenerational projects, 
this oral history archive refuses a unidirectional version of knowledge transmission and instead frames intergenerational memory as complex and multidirectional, with women and gender expansive people across ages nurturing each other as co-authors of their community stories. This work challenges dominant scripts of understanding and performing relationships across generations, to imagine new possibilities for intergenerational healing.

From the tongues of our Indo-Caribbean elders, we hear words, phrases and ways of communicating that originate from multiple places. When we try to trace their origins, we find ourselves on journeys that take us from our South Asian ancestors to our African-descended kin and the indigenous peoples of the Caribbean to Spanish, French, Dutch and British colonisers and back to the Caribbean. With little standardisation of spelling for the various forms of Creole and Creolese within and between countries, unique and often subtle variations in speech unlock context to the sub-narrative of the speaker. From the tongues of younger generations who have settled in the US, our elders hear fragments that might be recognisable, and others that remain lost in translation. Still, we listen.

By choosing oral history as the source of knowledge we wanted to share with our broader communities, we pay homage to these oral traditions that are so integral to Indo-Caribbean culture. On a universal level, oral history creates space for flexibility of expression, capturing emotions of the speaker that could not otherwise be conveyed. Furthermore, the oral history format allows for participants to share their stories in ways that mirror our community's historical practice of building collective knowledge. We work to preserve these stories in order to minimise the risk of them being lost to future generations. The oral history format intentionally considers the specific needs of the Indo-Caribbean community who, regardless of educational level or literacy, can gain access to the stories of their people.

Community archives are built to document, collect and make accessible the heritage that reflects the culture, experiences and 
identity of a shared community. The rise of oral histories as a method to create documentary heritage and preserve memory has also contributed to the growth of community archives. The discipline of oral history encourages both the collection of stories as an investment in community documentary heritage and as a tool for community building (Sheffield 2017). Our decision to build a community archive to hold the oral histories in our collection speaks to desire to retain control over the accessibility, description and interpretation of the stories within our community. We host the collected oral histories in an archival platform that allows storytellers to limit the audience to others within a shared community instead of the general public. By providing this option, we hope to encourage storytellers to share stories that are too often silenced.

\section{INTERGENERATIONAL SILENCES}

Arita: We have some of the same stories that our families tell us over and over again, but then there are the stories that they will never tell us. It's also about honoring those silences and when people don't feel ready to share their stories with anyone but themselves.

Kimmi: Thinking about stories as not just being this neutral place, it could be really dangerous to be breaking silences.

Sasha: There's this idea that by recognising these silences, we're also asserting some control on how the past is reconstructed.

With every story that is shared, there are countless others kept hidden or private. Patriarchy and other oppressive structures deeply rooted in society have declared what should and should not be known. Bahadur writes, 'The relative silence of coolie women in the sum total of history reflects their lack of power. But could it also reflect a strategy by women who had secrets to keep? Is it possible that, on some level, each individual silence has a 
plan?' (2013: 32). The construction of specific topics as taboo or shameful has perpetuated violence against women and gender expansive people for centuries. Storytellers who bravely choose to use their voice to speak up are placed at risk, a prime target for retaliation. Sharing stories related to queerness, familial hardships, assault, domestic violence, and substance abuse could result in anything from disownment to death. While it is not unique to Indo-Caribbean culture, the depth at which these stories are hidden results in dangerous consequences. The silencing of these stories, especially those of trauma and pain, is a direct factor in how cycles of violence and oppression continue to be reproduced and dismissed. It omits these experiences from the collective consciousness, burying them as if they never existed. There is danger in silence, but there is also danger in breaking the silence.

For the storyteller, the act of remembering can be evidence of resilience and a will to survive, but it can also jeopardise already fragile and tentative coping strategies (Field 2008). Speaking one's truth requires vulnerability, and silence is often used as a coping mechanism to repress memories that are too painful to remember. Research that attends to the functions of silence makes visible the ways in which silence is practised in order to resist efforts to co-opt and commoditise one's stories. Silence can indicate refusal to participate in a process that reduces complex lives to stories of trauma (Tuck and Yang 2014).

Nevertheless, the historical silencing of women and those of marginalised genders in Indo-Caribbean communities has led to a dearth of accessible and available histories by and about us. In addition, storytelling is often confined to particular spaces because of perceptions of what is 'appropriate' or 'inappropriate' for particular communities to speak about, or for safety reasons. Storytelling is not neutral, and we do not aim to simply elevate silenced voices to the same availability as others, but instead to carve out a space where those who might find healing in sharing their stories and listening to the stories of others can find a model. 


\section{COMMUNITY BUILDING THROUGH ARCHIVING}

Dharani: I think it's really powerful that we have been able to devise a way to ask the storytellers who they want to share their stories with, and be able to actually manufacture that in a digital way so they feel comfortable not only sharing their stories with whoever is recording them face-to-face, but also with the faceless audience that will come after and listen to it.

Arita: For me, I think a lot about not just about collecting the stories and having a huge collection of stories, but about what it means for the person who is sharing the story and also the person who's listening to the story, because I think in creating it all, we talked a lot about nurturing deep listening skills in the community and leaning into the reality that a lot of the times we don't know how to listen to each other and we don't trust each other to share our stories.

Sasha: There might be a lot of fear and unrest that someone might feel after they've had an interview. They might feel like they've been stripped raw and that all their secrets are out in the world and they don't know how to deal with their identity now. So we want to ensure that their needs are met and again, that we're forming a community.

Lissa: It doesn't really belong to any of us - I think what also really keeps us accountable is that there's not one owner of this.

As a community-owned archive, we inherently hold power in defining what 'community' means and which stories get told. The process of archiving stories is not simply about collecting and organising stories, but also about making deliberate choices about what to include and for what reasons. When the participants of the oral history workshop gifted us with their stories, we assumed a great responsibility to hold ourselves accountable to them and prioritise their needs. This requires being responsive to their desires about who they want their stories to reach, and who they want their stories to be hidden from. 
At the end of each interview, participants filled out consent forms where they were asked whether they consented to storing and sharing their interviews for the creation of a digital archive. If they consented to storing and sharing their interviews, they were asked to choose from a list of audiences they wanted to share their stories with, or to write in specific audiences that they would like their stories to reach. The options they were given to choose from were: public, anyone who identifies as Indo-Caribbean, only IndoCaribbean women and gender expansive people, and only other participants of the project. We provided participants with these options to honour that some participants were not ready to share their stories publicly but wanted community members who were experiencing similar struggles as they had in their lives to be able to access their stories as a resource. We were able to identify a content management software called Mukurtu, built by and for Indigenous communities seeking to preserve cultural heritage, which allowed us to manage privacy settings on each of the interviews so that we could honour people's boundaries around access.

The interviews were grounded in the concept of reciprocity and mutual vulnerability, as participants took turns serving both as listener and storyteller. In the workshop, we practised deep listening skills together, identified barriers we face in being able to share our stories, and reflected on our ongoing struggles with building trust with each other, particularly across generations. After completing their interviews, we asked participants whether there were topics that they still felt they were unable to talk about, and we reflected on who was missing from the room.

In November 2019, we hosted a launch event for the archive, which brought participants and community members together to listen to the oral histories, interact with the RbOS website, and be in conversation over themes that emerged. The participants voiced desires for us to expand the archive and include more stories from underrepresented groups within the diaspora. We reflected on the trauma that might resurface during an oral history interview and 
the importance of opening routes to healing so we can encourage community growth. We have moved forward with our work grounded in a sense of responsibility to these voices.

Our collective had many conversations about what our hopes were in joining this project and, for many of us, it was to join a group of Indo-Caribbean feminists committed to issues of justice. We have also thought about what it means to do oral history and archive work in a non-extractive way, and instead put energy into a healing process that comes from sharing stories. Central to this commitment is giving storytellers autonomy and ownership over their stories. Our praxis is grounded in several principles: archives should return stories to the communities they belong to; archives are always aspirational; they should be forward-looking and shift as new narratives beg to be written; they should prioritise choice, including the choice to be anonymous, to refuse, to stay quiet or retract; they must recognise when narratives that were meant to promote healing are doing damage; and they should be grounded in the desires of community members rather than institutions. Finally, in our work through this archive, stories can always be rewritten.

\section{ARCHIVES AS INCOMPLETE: VISIONS FOR THE FUTURE}

Sasha: We are in the middle of a pandemic and there are also just so many different health and racial inequities right now in our communities and in the US. We're not able to effectively grow our in-person communities because it might be unsafe to meet people in person, but I think recently we've been placing an importance on growing our virtual community.

Lissa: I really hope that we can also help develop resources so that other archives like us can sprout up and we can become a whole network of BIPOC women and gender expansive archives that are all like our cousins - all connected, a big network of sibling archives. 
Tarika: How can our work help deconstruct the anti-Blackness in our own communities and Indo-Caribbean communities, particularly an expansive sense of what being Indo-Caribbean means? Being IndoCaribbean doesn't have to mean being in opposition to Afro-Caribbean identities or being in opposition to Blackness. Through both the archive and the stories, it's very clear that people relate to that identity of being Indo-Caribbean in different ways, and they construct that identity in different ways.

Lissa: I want it to be normalised that radical stories of queerness, fighting patriarchy and existing as your full self can literally be alongside your auntie or your grandma's oral history. They can all live in the same space. They can live together and they deserve to live together.

As a collective, we hope that this archive will still exist, grow and evolve, beyond the involvement of the original group of co-authors. Our aim is not towards only capturing these stories in the moment but creating a sustainable path for those who come after us so that Ro(u)ted by Our Stories can continue to be a platform where people hear each other's stories and tell their own. With one of our major priorities being accessibility, we are working towards being able to provide people with anything needed to conduct their own oral history interviews in their communities - interview protocols, question guides, recording equipment and space. We do not believe it is our place to represent communities that are not our own. By creating these resources, tools, materials and processes, we hope that we can share knowledge with communities who want to develop and create their own community-owned digital archives.

As an archive just starting to grow its legs, there remain several gaps. All of the oral history interviews were collected from New York City residents, and all members of our collective are located within the US. Because the oral history workshop was conducted in a Hindu temple, we know we have work to do to centre the voices of our community members who do not feel welcome in this space. We envision a geographically expansive archive and 
hope to build connections with folks in the Caribbean, the UK, Canada and other spaces our people have migrated to. We also have work to do to understand how our practices might be excluding those from working-class, mixed-race and LGBTQ+ backgrounds, and those from other marginalised communities who have yet to see themselves represented in narratives about Indo-Caribbean history and identity.

While the latter part of our name points to our commitment to uplifting silenced voices, we do not know what that may look like in the future, or what people in the future may think of what we currently consider to be silenced voices. Perhaps in the coming years, certain marginalised identities will be normalised, and those listening to oral histories from the current time will shake their heads in wonder at the bigotry of the past. This does not seem entirely probable, but imagining these futures is the first step in manifesting them. Just as we draw on stories from our ancestors and elders, we hope those that come after us can draw on our stories for strength and knowledge-sharing. At the same time, our bodies themselves become a living archive and tribute to our experiences, and knowledge that cannot be spoken can also be shared through observation, affect and even the objects in our homes.

It's important to note that we are writing this in the middle of a global pandemic while also bearing witness to the uprisings in the United States and globally for the movement for Black lives. While resistance against racialised state violence and calls for change might currently be more visible to communities not directly impacted by anti-Blackness, movements to dismantle systemic racism have existed and endured since the moment these systems were created. We are again living in a moment where abolition has re-entered mainstream discourse, even as we see how the COVID-19 pandemic has exacerbated already existing inequities and upended our current way of life, demanding adaptability and new ways of orienting our societies, institutions and networks of care. Simultaneously (and relatedly) we call for the abolition of 
the police, the abolition of white supremacist patriarchal capitalism, the abolition of a system that never truly freed formerly enslaved Black Americans.

We have seen abolition of indentureship in 1917 increasingly becoming a focal point for Indo-Caribbean activists, historians and scholars, but abolition does not stop at our institutions of education and our established ways of knowing. An ethic of abolition, therefore, seeps into our conversation about the archive and the gatekeepers of knowledge. This has shaped how we think about the future of the archive and the ways in which we can leverage our resources to support ongoing movements for justice. At the start of the pandemic we realised that the digital spaces we had created as a geographically dispersed team were already set up for the transitions the world was making to more digital platforms in the wake of social distancing. Of course, other processes, like gathering stories by being in physical community with each other, may not be fully feasible for a while.

We continue to grapple with the question: how do we, as individuals and as an archive, support and uplift the expansiveness of Indo-Caribbean identity? As a member of our collective mentioned in the quote above, being Indo-Caribbean does not have to be in opposition to Blackness, but it's also important to acknowledge the existence of anti-Blackness in Indo-Caribbean communities. Being Caribbean holds different meanings for different people, and often embodies mixed heritages. How does our work challenge stereotypes and acknowledge shared histories? We find inspiration in Miriam Pirbhai's borrowing of 'pumpkin-vine affiliation' from Joy Mahabir's (2006) novel Jouvert. The 'pumpkin vine' is a common metaphor used in the Caribbean to describe extended networks of people who they are related to through birth, marriage, geographic proximity and other forms of kinship. As Pirbhai writes, it displaces the heteronormative, blood-related nuclear Indian family with a 'rhizomatic conception of community' (2010) of cross-racial alliances which takes seriously how our liberation is 
tied to the liberation of Black communities, indigenous communities and other groups living with the legacies of colonialism.

With these commitments in mind as we move forward, we end this piece with a quote from Mahadai Das's (1988) poem, 'Bones', which guides our thinking about stories and their desires to be told: 'Besides, these bones could make more than music / They're a fire-tried instrument. / They have no wish to stay in the attic./ They want to be part of the world.'

\section{ACKNOWLEDGEMENTS}

Thank you to the storytellers who shared their experiences with us. Thank you to Yasmin Toney and Shivana Jorawar for their involvement in this work at its earlier stages and their contributions to our thinking about oral history, digital archiving and community-building.

\section{REFERENCES}

Agrawal, Anuja. 1997. 'Gendered Bodies: The Case of the Third Gender in India', Contributions to Indian Sociology, 31 (2): 273-97.

Bahadur, Gaiutra. 2013. Coolie Woman: The Odyssey of Indenture (Chicago: University of Chicago Press).

Das, Mahadai. 1988. Bones (Leeds: Peepal Tree Press).

Field, Sean. 2008. 'Imagining Communities: Memory, Loss, and Resilience in Post-Apartheid Cape Town' in Linda Shopes and Paul Hamilton (eds), Oral History and Public Memories (Philadelphia: Temple University Press).

Gilroy, Paul. 1993. The Black Atlantic (Cambridge, MA: Harvard University Press).

Khan, Aliyah. 2016. 'Voyages across Indenture: From Ship Sister to Mannish Woman', GLQ: A Journal of Lesbian and Gay Studies, 22(2): 249.

Mahabir, Joy Allison Indira. 2006. Jouvert (Bloomington, IN: AuthorHouse).

Mehta, Brinda. 2006. 'Engendering History: A Poetics of the Kala Pani in Ramabai Espinet's The Swinging Bridge', Small Axe: A Caribbean Journal of Criticism, 10(3): 19.

Pirbhai, Miriam. 2010. 'The Jahaji-Bhain Principle: A Critical Survey of the Indo-Caribbean Women's Novel, 1990-2009', Journal of Commonwealth Literature, 45(1): 37-56. 
Sheffield, Rebecca. 2017. 'Community Archives' in Heather MacNeil and Terry Eastwood (eds), Currents of Archival Thinking (Santa Barbara, CA: ABC-CLIO).

Shepherd, Verene A. 2002. 'Constructing Visibility: Indian Women in the Jamaican Segment of the Indian Diaspora' in Patricia Mohammed (ed.), Gendered Realities: Essays in Caribbean Feminist Thought (St Augustine: University of the West Indies Press), 107-28.

Tuck, Eve, and K. Wayne Yang. 2014. 'Unbecoming Claims: Pedagogies of Refusal in Qualitative Research', Qualitative Inquiry, 20(6): 811-18.

\section{OTHER WORKS CONSULTED}

Crenshaw, Kimberle. 1991 'Mapping the Margins: Intersectionality, Identity Politics, and Violence against Women of Color', Stanford Law Review, 43(6): 1241-99.

Dabydeen, David, Maria del Pilar Kaladeen and Tina Ramnarine. 2018. We Mark Your Memory: Writings from the Descendants of Indenture (London: School of Advanced Study, University of London).

Hosein, Gabrielle Jamela, and Lisa Outar. 2016. Indo-Caribbean Feminist Thought: Genealogies, Theories, Enactments (Cham: Springer).

Kanhai, Rosanne. 1999. Matikor: The Politics of Identity for Indo-Caribbean Women (St Augustine: University of the West Indies, School of Continuing Studies).

Lorde, Audre. 1984. 'The Transformation of Silence into Language and Action' in Sister Outsider (New York: Cross Press).

Mohammed, Patricia. 2012. 'Changing Symbols of Indo-Caribbean Femininity', Caribbean Review of Gender Studies, 6. 